\title{
Antropofagia del desencanto: el cine y las relecturas del modernismo pos-1968
}

\author{
Cannibalism of Disenchantment: The Film and the
}

Rereading of Modernism Post-1968

Antropofagia do desencanto: o cinema e a releituras do modernismo pós-1968

\section{Vera Lúcia Follain de Figueiredo}

PONTIFÍCIA UNIVERSIDADE CATÓLICA DO RIO DE JANEIRO, BRASIL

Profesora de la Pontifícia Universidade Católica do Rio de Janeiro (PUC-Rio)

y doctora en Letras de la misma institución. Ha publicado Narrativas migrantes: literatura, roteiro e cinema (PUC/7 letras, 2010), Os crimes do texto: Rubem Fonseca e a fição contemporânea (UFMG, 2003) y Da profecia ao labirinto: imagens da história na fição latino-americana (Imago/UERJ, 1994). Correo electrónico: verafollain@gmail.com

\footnotetext{
Artículo de reflexión

El artículo se originó en el proyecto de investigación concluido y financiado por el Conselho Nacional de Pesquisa (CNPq) y fue presentado en el evento "Depois do modernismo", realizado en la PUC-Rio (2012). Traducción de Maria Cândida Ferreira de Almeida y Santiago Fernando Vásquez Morales (estudiante de Literatura de la Universidad de los Andes, Bogotá; correo electrónico: sf.vasquez279@uniandes.edu.co) Documento accesible en línea desde la siguiente dirección: http://revistas.javeriana.edu.co
} 


\section{Resumen}

Esta investigación analiza producciones cinematográficas que plantearon relecturas, en diálogo con otros lenguajes artísticos, de preocupaciones asociadas a la búsqueda de un estilo que expresara lo "propio" de una identidad brasileña. La autora presenta el movimiento cinematográfico de los sesenta, su relación con las producciones literarias del treinta y sus referentes conceptuales. Así mismo, analiza películas del periodo para evidenciar la permanencia de tópicos como la antropofagia y el tropicalismo, que dan respuesta a preocupaciones tanto políticas como artísticas, en un debate que se mantiene vigente.

Palabras clave: modernismo, cine nuevo, antropofagia, tropicalismo.

Palabras descriptor: Identidad, modernismo, antropofagia, cine brasileño.

\section{Abstract}

This research examines film productions, which established rereading, in dialogue with other artistic languages, of concerns associated with the search for a way to express the characteristic of Brazilian identity. The author presents the film movement of the $60 \mathrm{~s}$, the dialogue with the literary productions of the 30 ', with their conceptual referents, and analyze films of period to demonstrate the permanence of topics such as antropophagy and tropicalism, which respond to both political concerns artistic, in a debate that is still valid.

Keywords: modernism, cinema novo, antropophagy, tropicalism. Keywords plus: Identity, modernity, cannibalism, movingpictures, brazilian.

\section{Resumo}

Esta investigação analisará produções cinematográficas que propuseram releituras, em diálogo com outras linguagens, de preocupações associadas à busca de um estilo que expressasse o "próprio" de uma identidade brasileira. Apresentar-se-á o movimento cinematográfico dos anos 60 , o diálogo com as produções literárias de 30, seus referentes conceituais e se analisará filmes do período para evidenciar a permanência de tópicos como a antropofagia e o tropicalismo, dão respostas a preocupações tanto políticas como artísticas, em um debate que se mantém vigente.

Palavras-chaves: modernismo, cinema novo, antropofagia, tropicalismo.

Palavras-chave descritores: Identidade, Modernismo, canibalismo, cinema brasileiro.

RECIBIDO: 6 DE MARZO DE 2013. EVALUADO: 1. ${ }^{\circ}$ DE MAYO DE 2013. ACEPTADO: 2 DE MAYO DE 2013.

\section{Cómo citar este artículo:}

Follain de Figueiredo, Vera Lúcia. "Antropofagia del desencanto: el cine y las relecturas del modernismo pos-1968". Cuadernos de Literatura 18.35 (2014): 103-118. 


\begin{abstract}
"Oswald es la posibilidad de una cultura crítica, fuera del oficialismo, del lirismo, del romanticismo político. Es la devoración antropofágica de todos los mitos creados para impedir el contacto de este país con la realidad e inventar su historia".
\end{abstract}

JOSÉ CELSO MARTINEZ CORRÊA

SuRgido a finales de los años cincuenta, el cinema novo (cine nuevo), además de buscar un lenguaje cinematográfico capaz de expresar la realidad brasileña, se comprometió con el proyecto de transformación del país según el ideario de la intelectualidad de izquierda. Para los cineastas comprometidos con las causas sociales, el cine habría de utilizar elementos de la cultura popular, expresión que, en aquel momento, significaba tanto la producción cultural que viene del pueblo como aquella que a él se dirige, asumiendo la defensa de sus intereses. Al mismo tiempo, el sentido de lo popular estaba íntimamente vinculado al de lo nacional, y, en función de esto, la quintaesencia del pueblo era buscada en aquel integrante de la sociedad menos contaminado por injerencias exteriores, es decir, en el hombre del mundo rural. Esto explica el protagonismo de dicho personaje en la ficción cinematográfica de la época y la extensión del espíritu campesino para el migrante favelado (de la barriada, del barrio), ya que la favela es vista como un ambiente semirrural.

En el campo del arte, se trataba, entonces, de encontrar el camino más adecuado para consolidar un estilo brasileño, que expresase lo más auténtico que había en nuestra cultura, sin dejar de denunciar las contradicciones de la realidad, y contribuyera a transformarla. En el esfuerzo para encontrar ese estilo brasileño, el cine nuevo, aunque compartiese con todo el movimiento modernista brasileño el propósito de descolonización de la cultura, tomó como modelo principal la literatura modernista de los treinta, lo que se confirma en la siguiente afirmación de Glauber Rocha:

Lo que hizo del cine nuevo un fenómeno de importancia internacional fue justamente su alto nivel de compromiso con la verdad; fue su propio miserabilismo, que, antes escrito por la literatura de los treinta, fue ahora fotografiado por el cine de los sesenta; y si antes era escrito como denuncia social, hoy pasó a ser discutido como problema político. (65)

Las palabras de Leon Hirszman refuerzan la declaración anterior:

El cine nuevo participaba también del proceso más amplio de la cultura brasileña en este siglo, siguiendo los caminos abiertos por la literatura regional de los años treinta, de corte periodístico, que correspondía, en el plan político, 
a la Revolución del 30. Graciliano Ramos, Jorge Amado, José Lins do Rego y Érico Verísimo intentaron cada uno a su modo expresar la recuperación de la realidad social y popular de sus regiones. Esta literatura presentaba características universales, al proponer una nueva representación del modo de ser brasileño. (25)

Si la recurrencia a la literatura de los treinta era estimulada incluso por el contacto de los cinenuevistas con el neorrealismo italiano, el modernismo de la década del veinte quedaba en segundo plano, lo que generó evaluaciones contradictorias. Así, en entrevista concedida a Raquel Gerber, en febrero de 1973, Glauber Rocha dijo:

Yo llamo al movimiento del 22 "de estética liberal del café". Es una manifestación ejemplar del liberalismo burgués, pues en el 22, además del arte moderno, hay el tenentismo y el surgimiento del PC [Partido Comunista], sin que haya entre estos hechos ninguna integración. Cuando la Columna Prestes ${ }^{1}$ estaba aconteciendo, los artistas, las personas cultas de São Paulo, estaban tratando sobre la reforma del verso. (Gerber, Gardies et al. 12)

Ya en un artículo incluido en Revolución del cine nuevo, compilación publicada en 1981, que se constituye en un balance del movimiento del cine nuevo, Glauber afirmaba: "El tropicalismo, la antropofagia y su desenvolvimiento son la cosa más importante hoy en la cultura brasileña" (150). Y agregaba:

Tropicalismo es la aceptación, ascensión del subdesarrollo; por esto existe un cine antes y después del tropicalismo. Ahora nosotros no tenemos más miedo de afrontar la realidad brasileña, nuestra realidad, en todos los sentidos y con todas las profundidades. Esto porque en Antonio de las muertes existe una relación antropofágica entre los personajes: el profesor se come a Antonio, Antonio se come al cangaceiro $^{2}$, Laura se come al comisario, el profesor se come a Claudia, los asesinos se comen al pueblo, el profesor se come al cangaceiro. (150)

1 Columna Preste: marcha que atravesó todo Brasil, de 1925 a 1927, en busca de cambios políticos y sociales, además de enfrentar al Gobierno con armas. Su líder más conocido fue Luiz Carlos Prestes.

2 Cangaceiro: participante de un movimiento armado de lucha contra el Gobierno y los terratenientes propio de una región de Brasil, el Nordeste, desde fines del siglo XIX hasta 1930. 
Como se ve, antropofagia y tropicalismo ${ }^{3}$ son empleados, en la anterior cita, prácticamente como sinónimos. Pasado el periodo de la euforia revolucionaria, las ideas de Oswald de Andrade son rescatadas por Glauber, pero en un diapasón distópico. La devoración se vuelve sinónimo de la continua canibalización del hombre por el hombre, al contrario, por ejemplo, del rescate de la antropofagia hecho por Antonio Callado, en Quarup. En este libro, escrito en 1966 y publicado en 1967, año en el que inció el tropicalismo, el protagonista actúa en estos últimos instantes con la esperanza de revertir la situación política, después de la derrota con la instauración de la dictadura militar. En las vísperas de partir para la lucha armada, el personaje Nando organiza un banquete antropofágico en el cual devora la memoria de Levindo, estudiante muerto en la lucha en defensa de los campesinos. En lugar de los mitos impuestos por la cultura de la clase dominante, quedará el mito de Levindo, cuyo nombre será la palabra generadora a ser deletreada, aprendida por los oprimidos, porque a partir de ella se inaugura un nuevo lenguaje. Habiendo completado su proceso de deseducación, librándose de la cultura libresca que lo separaba del hombre sencillo, Nando, vestido de cangaceiro, comprometido con la guerrilla, anuncia un nuevo tiempo, en que el brasileño empezaría a construir su historia.

A partir de $1968^{4}$, entretanto, las lecturas tropicalistas de la antropofagia sirvieron a diferentes propósitos, y respondieron de maneras diversas no solo a las mudanzas en el contexto político y económico ocurridas con la dictadura militar, sino también a los cambios en la esfera de la cultura, derivados de la persecución a los artistas de izquierda y de la censura, así como también de las inversiones del Estado en el área de las telecomunicaciones, que permitieron a la televisión consolidarse como un vehículo de masa. Renato Ortiz (186) recuerda que en 1965 Brasil se asocia al sistema internacional de satélites (Intelsat) y que en 1967 es creado el Ministerio de las Comunicaciones. Señala también el fortalecimiento

3 El movimiento tropicalista, que tuvo vigencia en el periodo entre 1967 y 1972, y se expandió por diferentes campos de la producción cultural, tomó su nombre de una instalación del artista plástico Hélio Oiticica, realizada en 1967, pero ganó notoriedad, sobre todo, a través de la música popular. Caetano Veloso y José Celso Martinez Corrêa, además del propio Hélio Oiticica, compartían, en aquel momento, la convicción de que era necesario formular un nuevo proyecto de vanguardia que reflejase los cambios ocurridos en la realidad brasileña.

4 En diciembre de 1968, el Acto Institucional n. ${ }^{\circ}$ 5, o AI-5, autorizó al presidente de la República para decretar el receso del Congreso Nacional; intervenir en los estados y municipios; terminar mandatos parlamentarios; suspender, por diez años, los derechos políticos de cualquier ciudadano; decretar el decomiso de bienes considerados ilícitos; y suspender la garantía del hábeas corpus. Se inició, entonces, el periodo más represivo del régimen militar, considerado como el golpe dentro del golpe. 
del mercado de bienes culturales desde mediados de 1960. La modernización conservadora emprendida por los gobiernos militares siguió, así, su rumbo.

En ese escenario, el espíritu desconstructor del modernismo de los años veinte y particularmente el pensamiento de Oswald de Andrade son rescatados, con el fin de componer una imagen disonante del Brasil que se contrapusiera a la imagen armónica que la dictadura intentaba mostrar apropiándose de los mitos románticos. En ese sentido, cabe recordar la parodia del nacionalismo sentimental y de su lenguaje idílico hecha por Gilberto Gil y Torquato Neto en Márginália II:

$$
\begin{aligned}
& \text { aqui el terceiro mundo } \\
& \text { pede a bención vai dormir } \\
& \text { entre cascatas palmeiras } \\
& \text { araçás y bananeiras } \\
& \text { ao canto de la juriti } \\
& \text { aqui meu pano de glória } \\
& \text { aqui meu laço y cadeia } \\
& \text { conheço ben minha historia } \\
& \text { começa en la lua cheia } \\
& \text { e termina antes del fim } \\
& \text { minha terra ten palmeiras } \\
& \text { onde sopra el vento fuerte } \\
& \text { da fome con medo muito } \\
& \text { principalmente de la morte } \\
& \text { o le le lá lá }
\end{aligned}
$$

El humor y la irreverencia de los textos de Oswald inspiraron el tratamiento irrisorio conferido al nacionalismo exacerbado de la propaganda gubernamental. La tonalidad serio-dramática de la literatura de los años treinta fue sustituida por el estilo anterior, es decir, por el tono jocoso e irónico de la vanguardia de los años veinte ${ }^{5}$. Sin embargo, la diferencia entre los dos momentos históricos otorga otros sentidos a la herencia dejada por el primer modernismo. En algunas músicas y películas del inicio del tropicalismo, la antropofagia fue releída bajo el signo del resentimiento, de la amargura derivada de la derrota política sufrida con

5 Nelson Pereira dos Santos, que en 1963 adaptara Vidas secas, de Graciliano Ramos, al cine, dirigió Como era gostoso o meu francês (1971), sintonizándose con la retoma de la antropofagia por la estética tropicalista. La película hace una lectura irreverente de la historia colonial brasileña, inspirándose en el relato del alemán Hans Staden, que a mediados del siglo XVI fue tomado prisionero por los tupinambás. 
el golpe militar de 1964. La antropofagia de Oswald se constituía en un proyecto de descolonización de la cultura a través de la canibalización de las tradiciones europeas, que abriría un espacio para la elaboración de nuevas representaciones con el objetivo de erradicar nuestro complejo de inferioridad. A través de la antropofagia, se redefinió la relación colonizador/colonizado, y se tribuyó al segundo el papel activo de devorador de la cultura impuesta por el primero. Esa no es la visión que orienta, por ejemplo, la adaptación de Macunaíma para el cine, realizada por Joaquim Pedro de Andrade en 1969. Interesaba al director, que se distanciaba de la utopía oswaldiana, filmar la historia de un brasileño devorado por el Brasil, con el objetivo de denunciar la antropofagia institucional, los mecanismos de devoración camuflados en la selva capitalista. Sobre la película, dijo José Carlos Avellar:

"Brasil empezaba a comerse más a los brasileños", cuando Joaquim Pedro de Andrade filmó la historia de Macunaíma, "un brasileño que fue comido por el Brasil", con el personaje que gritaba, en medio de la calle, el lema que definió bien el estado de cosas que se posicionó entonces: "cada uno para sí y dios contra todos "; con la diosa Ci de la novela de Mário de Andrade transformada en guerrillera urbana; y con el héroe en un duelo con el villano, el gigante Wenceslau Pietro Pietra, sobre un inmenso caldero de frijolada antropofágica -los frijoles sazonados con trozos de carne humana-. (144)

Pasados los tiempos de esperanza, la obra de Mário de Andrade es rescatada porque, en ella, quien devora es el villano: se trata, en la película, de destacar la antropofagia de los más fuertes. Para Joaquim Pedro, la película tematiza la permanencia de la antropofagia en la sociedad brasileña, lo que significa que "las relaciones entre las personas permanecen iguales desde los tiempos en que realmente se practicaba la antropofagia directa, sencilla y salvaje hasta los días actuales en que esta antropofagia gana un aspecto civilizado" (Ramos 56). Se nota que la antropofagia, allí, es leída en un diapasón negativo, en conformidad con la crítica corrosiva del país en un momento en que el sistema se apoderaba de todos los signos de lo nacional-popular, para ponerlos al servicio del conformismo. Hasta el término revolución fue apropiado por la dictadura que con él designó el golpe militar. Además de esto, comenzó a consolidarse, a lo largo de la década del sesenta, una cultura nacional-popular de mercado, que tomó para sí la misión de llevar el pueblo a las pantallas y se apropió de la bandera de la identidad nacional en el combate contra el enemigo externo, otra vez identificado con el comunismo. Añádase a esto que la creencia en el carácter libertario del progreso industrial y tecnológico que caracterizó las vanguardias de los 
años veinte y cincuenta también fue abalada, ya que el régimen se apropió de la bandera de la modernización.

Da allí que el retorno a la paradoja primitivo/moderno promovido por los cineastas contrarios al régimen se realizara en otra perspectiva, diferente de la asumida por Oswald de Andrade, para quien la antropofagia era la clave para superar tanto el idealismo nacionalista romántico como el pesimismo determinista que contaminó a los intelectuales de finales del siglo XIX, influenciados por el cientificismo etnocéntrico europeo. La fórmula encontrada, combinando sentimiento nacionalista y cosmopolitismo, prefiriendo el híbrido en detrimento de las categorías puras y excluyentes, nació de la necesidad de crear nuevos parámetros de pensamiento que nos permitieran sobrepasar las dicotomías que venían sustentando el pensamiento sobre la cultura en el país y que actualizaban siempre el mismo esquema: o la defensa de un nacionalismo esencialista y cerrado o la apología de un universalismo modernizador que significaba completa sumisión a los modelos europeos. Oswald de Andrade valorizó el efecto singular de nuestras mixturas y anacronismos, marcando como positivo aquello que, entre nosotros, resistió a la aceleración del tiempo y que no necesariamente debería ser visto como atraso. Al contrario, proponía la posibilidad de considerarlo como resistencia a una modernización pautada por el ritmo de los negocios, por la mentalidad pragmática y competitiva del hemisferio norte. La convivencia de lo arcaico y de lo moderno en los textos del modernista apuntaba, entonces, hacia un anacronismo positivo, es decir, la permanencia de trazos arcaicos de nuestra sociedad era hasta cierto punto ventajosa, pues permitiría un contrapunto crítico a las leyes modeladoras de la civilización europea, lo que contribuiría a la constitución de una historia paralela a la de Occidente.

En los años setenta, el renacimiento de los arcaísmos, por lo menos en lo que concierne a un determinado sector de la producción cinematográfica, tenía sobre todo una función desmitificadora: la yuxtaposición arcaico/moderno sirvió a la crítica de la modernización de superficie que dejaba intactas las bases de la desigualdad social, y llamaba la atención sobre el avance depredador del capitalismo brasileño. Por otro lado, se combatía también la idealización de un Brasil profundo, auténtico, que cabría rescatar para, a partir de él, construir un país moderno, como proponía el ideario nacional-popular. Así, en 1974, momento en que la dictadura militar, con la finalidad de reforzar el patriotismo exacerbado y conservador, incentivaba la realización de películas históricas y adaptaciones de la literatura brasileña, y prometía darle prioridad en el planeamiento presupuestario al órgano gubernamental de producción cinematográfico, llamado Embrafilme, Jorge Bodansky y Orlando Senna releyeron, 
en un registro profundamente cáustico, el pasaje del personaje de Alencar, en Iracema, uma transa amazónica ${ }^{6}$.

La película fue realizada en un contexto político en el que se vendía la idea de un país que iba para adelante, y que había recuperado, después de la amenaza desintegradora del comunismo extranjero, el rumbo del progreso. Si, en el discurso de la dictadura militar, vencer distancias espaciales, construyendo la Transamazónica, significaba llevar el futuro a las regiones lejanas, el director optó por un road movie para retratar los efectos devastadores provocados por la modernización de fachada en el Brasil del interior. El personaje Tião Brasil Grande es un camionero que atraviesa el país, vendiendo madera y llevando a los lugares más distantes el discurso de exaltación del proyecto modernizador de la dictadura militar, a través del cual enaltece también su propia actividad comercial. Entretanto, la dicción cínica y el tono provocador que puntúan su verbalización de la fe en el futuro, juntamente con las imágenes desoladoras de los lugares por donde pasa el camionero, captadas por una cámara documental, denuncian el engaño de la retórica del poder. Esa actualización paródica del drama de Iracema, a mediados del siglo XX, tiene como efecto llamar la atención del espectador hacia una historia que no avanza, sino que, al contrario, se repite de manera degradada.

Como el personaje romántico, la Iracema de Jorge Bodansky y Orlando Senna también se desplaza en el espacio, alejándose de los referentes de origen. Es obligada a dejar de ser lo que era sin conseguir pertenecer, en condiciones de igualdad, a la cultura dominante; para arreglárselas en medio de las adversidades, se vuelve prostituta. Se trata otra vez de la tierra-mujer ofrecida en sacrificio en nombre de un modelo de modernización traído de lejos, que no fue sedimentado paulatinamente a partir de los intereses locales. Solo que, en la relectura realizada por los directores, la relación erótica mediada por el dinero y no por el amor romántico es estéril, no genera fruto. Sin Moacir, hijo del personaje romántico, el sacrificio de Iracema en el altar de las "prácticas civilizatorias" es en vano, no engendra el futuro. El progreso anunciado por la publicidad del Gobierno pasa por las pequeñas localidades como el camión de Tião Brasil Grande: no las fertiliza y deja un rastro de destrucción. El Brasil de Tião devora las Iracemas.

Por otro lado, el tropicalismo, que se asumió poco a poco como un movimiento crítico cuyo énfasis no estaba en una militancia de oposición, recurrió al binomio originalidad nativa y técnica para combatir el arte nacional-popular, cuya

6 Como la película ponía al descubierto la propuesta del gobierno, al asumir una postura crítica con relación al discurso oficial, fue impedido su lanzamiento en Brasil, y apenas fue permitido en 1980 . 
excesiva preocupación por el contenido había contribuido a la pobreza estética, a la flexibilización con respecto a los aspectos formales de las obras, al mismo tiempo en que habría también fracasado en su estrategia de concientización del público a través de la identificación emocional con el oprimido. Terra em transe, película de 1967, por ejemplo, marca el cambio de postura de Glauber Rocha en relación con lo nacional-popular, a través de la figura quijotesca del personaje Paulo Martins.

En la música, la vanguardia tropicalista tomaba la bandera de la revolución estética, asociada al mensaje rebelde y anárquico, sin dejar de coquetear con la cultura de masa, con lo que buscaba alcanzar un público más grande: se trataba de conciliar "antropofágicamente" las innovaciones musicales con la popularidad mediática. El elogio del progreso técnico y de los hibridismos contra los ideales de pureza, promovido por el modernismo brasileño, se volvía bastante conveniente para algunos artistas en esta época en que el mercado de bienes culturales se ampliaba y la televisión abría nuevos horizontes de trabajo. En esta perspectiva, la antropofagia, en el proceso de revisión cultural que ocurría a partir de finales de los años sesenta, pasaba a servir también a la integración del artista al mercado en expansión. La yuxtaposición de elementos dispares en las canciones, que ponían lo "cursi" y la modernización traída por la técnica uno al lado de la otra, se justificaba como reacción "al banquete aristocrático de la inteligencia brasileña", para usar las palabras de Luiz Carlos Maciel (Favaretto 12), y llevaba a la superficie elementos de la cultura popular despreciados por las élites. Sin embargo, la mixtura tropicalista en el campo musical, con su carácter lúdico y cosmopolita, que enfatizaba el efecto humorístico en uno de los momentos más feroces de la represión promovida por la dictadura militar, tuvo resultados ambiguos, en función, incluso, de su impacto en la cultura de masa. Se alejaba, así, en varios aspectos del proyecto cultural de Oswald de Andrade. En este, la concepción abierta de cultura, la absorción y la transformación de elementos ajenos apuntaban al perfeccionamiento de la cultura brasileña, es decir, la perspectiva crítica no perdía de vista el horizonte utópico: la técnica servía para la liberación; el bárbaro tecnificado era el hombre que, adquiriendo el dominio de la técnica sin dejar a un lado sus características culturales, se volvía libre. El "Manifiesto antropófago", visto desde este ángulo, era un canto futurista: la agitación del contexto interno, aunque más concentrada en São Paulo, para exigir cambios políticos y económicos, y la industrialización creciente suscitaban la esperanza de que podríamos "acomodar el reloj con la contemporaneidad". No obstante, al valorizar aquello que, entre nosotros, no se compatibilizaba con el modelo racional de los países hegemónicos era también un canto primitivista. Al asumir 
la paradoja primitivo-modernista, Oswald adoptaba una óptica culturalmente descentrada: el reconocimiento de la importancia de la técnica servía para neutralizar la tentación de interpretar cómodamente el atraso como manifestación de una fuerza creadora original, no contaminada por los vicios europeos. Con ese espíritu, el modernismo brasileño imprimió nuevo vigor al nacionalismo y revisó críticamente los mitos románticos para crear una imagen del Brasil que permitía reconciliar la nación real con la nación ideal.

En el movimiento tropicalista, la postura crítica en relación con el nacionalismo no significaba rechazarlo radicalmente, lo que estaba en sintonía con el ideario del modernismo del 22, sino que tenía, en el campo cultural, un blanco más inmediato: el romanticismo nacional-popular de las izquierdas de los años sesenta. En este sentido, "no se trataba de resistir a la industria cultural y a la dictadura encerrándose en el pasado, sino de enterrar la cabeza en las estructuras para subvertirlas por dentro", como observó Marcelo Ridenti (284). Era en este punto que el vanguardismo tropicalista se volvía más ambiguo: se afirmaba cada vez más como un movimiento por encima de las ideologías, crítico, al tiempo que, impúdicamente festivo, se proponía devorar el mercado estando dentro de él. La antropofagia, ahora, abría espacio para la integración contradictoria del artista en la otra cultura nacional-popular -la de mercado-, que tenía en el canal de televisión Globo su gran exponente; y, al hacer el elogio de la libre competitividad, preparaba también el camino de la apertura para el mercado internacional.

La problemática relación entre el mercado cultural interno y el externo, entretanto, ya constituía una preocupación para Oswald de Andrade en la década del cuarenta, cuando se refirió a un nuevo fenómeno: una "invasión" de la cultura de masas norteamericana. En "Carta abierta a Monteiro Lobato", publicada como artículo de periódico, volvió al pasado para señalar la oposición que se estableció en 1918 entre los avances tecnológicos que acortaban distancias y el nacionalismo de Lobato, en Urupês -libro editado en aquel año, en el cual surge la figura del campesino Jeca Tatu-. Oswald declaró entonces: "Y mal sospechábamos -yo y usted y los otros frecuentadores de aquel refugio de la ciudad, que nos parecía volcánica en los tímpanos aún recientes de la Light and Power- que una oposición empezaba entre su libro y el avión" (Ponta de lança 33). Y más adelante afirmaba:

Pero alrededor de usted empezó a subir la tonada mecánica de trillos y claxon de la ciudad moderna, empezó el cine a pasar, a parpadear el anuncio

7 Con respecto a esta misma carta, véase el ensayo "Literatura e cultura de massa", del libro $O$ cosmopolitismo do pobre de Silviano Santiago. 
luminoso, el radio a desgañitar reencuentros y goles. Y los niños poco a poco a distraerse. Uno fue a ver a los Escuadrones de la madrugada. Otro, el Imperio submarino. Un tercero, con los dientes en mudanza, abrió la boca porque Leonidas se había machucado el dedo grande del pie izquierdo. (36)

En seguida, concluía: "Lobato, se traba una lucha entre Tarzán y la Emilia [personaje de Lobato más conocido]" (36). La lucha a la que se refería Oswald era la derivada de la modernización desigual, que impulsaba el progreso de São Paulo, tributario de la Light and Power, y dejaba por fuera al Brasil del interior. La cultura de masa norteamericana entraba en Brasil con toda la fuerza a través del cine y de las tiras cómicas, atropellando los emprendimientos de Monteiro Lobato orientados hacia la creación de un mercado editorial interno, hacia la divulgación de la cultura letrada nacional. Es decir, el escritor modernista señalaba el problema de la no-sincronía entre nuestro ritmo de producción industrial y de distribución de bienes culturales y el ritmo de los países hegemónicos.

El choque entre Tarzán y Emilia señalaba, para Oswald, el enfrentamiento en un campo más vasto, es decir, el choque entre dos proyectos opuestos de modernización: uno que nos dejaba a merced del "capitalismo de vista corta y uñas largas" (37) y otro en el que el país tomaría las riendas del ritmo de sus cambios, es decir, de su propia temporalidad. Era preciso, entonces, quedar fuera del alcance de la "pata gigantesca y astuta de los intereses excusos" (36) que amenazaban los emprendimientos editoriales de Lobato y, al mismo tiempo, enviaban a Jeca, habitante del mundo rural, excluido del proceso de modernización, a la guerra, al convocarlo a participar de la coyuntura internacional como soldado. Es decir, iba a dar la sangre por la redención de Europa, a alzarse en armas, mientras le negaban el acceso a los libros y a los beneficios del progreso técnico.

Hombre urbano, cosmopolita, Oswald no era un entusiasta incondicional de la cultura técnica en expansión, aunque reconocía en ella un potencial emancipador. Se preocupaba por el destino de Jeca, esa figura que en verdad ni llegaba a participar del choque entre Tarzán y Emília, pues no fue alfabetizado y no iba al cine, sino que, como dijo Oswald, "trabajó el sertón y la ciudad", e hizo el Brasil. En la carta a Monteiro Lobato, nuestro modernista buscaba pensar la experiencia de atropello vivida por los países periféricos ante la aceleración de las innovaciones en los campos industrial, tecnológico y científico. Por un lado, el avance de la técnica podría permitir que acoplásemos el reloj con la contemporaneidad, y hacer un guiño a la posibilidad de escaparse de una visión de la historia sucesiva y lineal, que nos condenaba a tener que vivir con atraso cada etapa ya experimentada por las naciones hegemónicas. Por otro, la tecnología invasora, en ritmo 
irrefrenable, creaba nuevos ambientes y alteraba los rumbos de la cultura local, como los aviones que, sobrevolando São Paulo, afectaban, sin que se percibiese, la recepción de Urupês.

Para Oswald de Andrade, en aquel momento marcado por la II Gran Guerra, lo más importante era no dejar a Jeca a merced de la tecnificación que venía de fuera, pues esto significaría condenarlo a la exclusión, sacrificarlo en función de los intereses del mercado financiero internacional. La época del fotomontaje, que traía una nueva manera de percibir el tiempo -como convergencia de momentos, como simultaneidad de los instantes- debería ser aprovechada de modo que nos permitiese beber de un trago solo nuestra independencia técnica y, entonces, sería el momento de que Jeca hablara y se hiciera valer, en vez de las oposiciones excluyentes que sustentaban el pensamiento moderno, la lógica acumulativa: es decir, la floresta y la escuela, el álgebra y la química después de la aromática de manzanilla. Jeca no sería más desigual y vermicular, como lo describió Lobato, y sí un ciudadano que concebiría las innovaciones tecnológicas como fruto de una elección y no como fatalidad. El Jeca que devoraría tanto a Emilia, muñeca hablante, como a Tarzán, rey de la selva africana, sin tener que olvidar "el duerme nené que el bicho viene y te atrapa", la sabia pereza solar, el rezo y el carnaval. Finalmente, el Jeca antropófago, consciente de que hay una no-sincronía positiva.

Después del modernismo, la convivencia de lo arcaico y de lo moderno, así como la posibilidad de superar nuestros descompases temporales a través del avance técnico, cuestiones discutidas por Oswald de Andrade, serán retomadas a lo largo del tiempo tanto en el campo de la reflexión teórica como en el campo del arte. La permanencia del tema de nuestra no-sincronía -sea para destacar que es preciso dar un salto en el tiempo, sea para señalar la contrapartida ventajosa del descompás- apunta hacia la desconfianza en una modernización que, con el traslado de intereses externos al país, sería siempre de fachada y enmascararía problemas de base. Así, en su libro de 1996, el geógrafo Milton Santos marcó positivamente la resistencia a lo que él llama "sincronización despótica", de "reloj del mundo instigado por la competitividad a escala global", que penalizaría a quien, con él, no acertara en el paso. De ahí su elogio al hombre lento. Según Milton Santos, los hombres lentos, los pobres de la ciudad, escaparían al totalitarismo de la racionalidad, aventura vedada a los ricos y a las clases medias. La carencia llevaría a la creación de nuevos usos y finalidades para objetos y técnicas, pues el consumo imaginado, pero no atendido, produciría la falta de confort creador. El choque entre cultura objetiva y cultura subjetiva se volvería instrumento de una nueva conciencia $\left(5^{2}\right)$. 
En el cine más reciente, la película Cine, aspirinas y urubus (Brasil, 2003), de Marcelo Gomes, retoma el tema de las relaciones del hombre del interior con la técnica. La historia narrada por la película se sitúa en el sertón nordestino, en 1942, en plena Segunda Guerra Mundial. Las aspirinas del título, distribuidas en el Brasil por un alemán fugitivo de la guerra, son vendidas en el sertón, con el auxilio de una pequeña película publicitaria, como panacea capaz de curar todos los males. La aparición abrupta del cine en aquella región inhóspita, sin que tuviese ningún vínculo con la cultura local, sin que tuviese conocimiento de su contexto de producción, más allá del contenido de la película publicitaria exhibida, envuelve a la población del lugar en una atmósfera mágica que acaba por legitimar el milagro prometido con el consumo de los productos de Bayer. El efecto sorpresa deriva de la distancia cultural entre el objeto técnico y el medio en que es introducido, que crea en torno de él un misterio, hace que deje de ser un simple objeto y le imprime una especie de fuerza oculta. En la película de Marcelo Gomes se llama la atención sobre la manera como los objetos técnicos que vienen de afuera interfieren en las formas de vida de un lugar y, al mismo tiempo, sobre el modo en que cada lugar se va relacionando con esos objetos a partir de su sistema de referencias.

Johann, el alemán, y Ranulpho, el del sertón, personajes principales de la película, se cruzan en el momento fugaz, antes de tomar direcciones radicalmente opuestas. Así, si Johann va para Brasil, huyendo de un modelo de modernización que, además del culto de la tecnología con un nacionalismo de bases míticas, llevó a su país a la guerra, en sentido inverso Ranulpho, el sertanejo, abandona la tierra natal, el lugar donde nació, y sale en busca del progreso, fascinado con sus promesas. La guerra lleva hacia al interior al alemán Johann, que huye de los campos de batalla, e, indirectamente, fortalece las condiciones para que Ranulpho se encamine para la ciudad grande, conduciendo el camión regalado. Ranulpho busca aquello de lo que el alemán quiere escapar: “iEn Brasil, ni la guerra llega!", reclama él.

El retroceso de Johann en dirección a la naturaleza, que culminará con su ida para la Amazonia, y el avanzar de Ranulpho rumbo a la "civilización", de un lado, propician el encuentro y, de otro, los desencuentros, expresados bajo el signo de la violencia, de los cortes abruptos en las historias individuales. Son tiempos diferentes que se cruzan, pero ambos personajes están en fuga -fuga de los desmanes de la racionalidad occidental que usa la técnica para perfeccionar armas mortíferas y fuga de las agruras del medio hostil, no dominado por el hombre-. La ruptura con el pasado, con el origen, sumerge a los personajes en la soledad. En la estación de tren, a partir de la cual las trayectorias encontradas 
se apartan, la focalización del cielo cortado por urubús deja claro que ni el retorno a la naturaleza ni tampoco el espacio urbano y la racionalidad tecnológica son garantías de un futuro promisorio para aquellos individuos solitarios en su búsqueda.

La ficción cinematográfica brasileña ha destacado de esta forma que la simultaneidad y unicidad de las tecnologías, alcanzadas a lo largo del siglo XX, no se realizaron en la dirección de la creación de un mundo más igualitario, en el cual se redujese el abismo entre países periféricos y países hegemónicos, porque, a pesar de todas las crisis, aún son estos últimos los que detentan el conocimiento científico y tecnológico. Como se ve, si las cuestiones puestas de presente por el modernismo brasileño son recurrentemente retomadas, la terca utopía de Oswald de Andrade parece haber quedado atrás. Está lejos el tiempo en que se podía refrendar la siguiente afirmación de nuestro modernista:

Abordando el clímax de la técnica, el calvinismo, que fue, con la doctrina de la gracia, el instrumento del progreso, tiene que ceder el paso a una concepción humana e igualitaria de la vida, esa que nos fue dada por la Contrarreforma. La técnica pasa de la fase de perfeccionamiento a la conquista de mercados, llevando al África más remota, a las islas de Oceanía, el mismo libro y el mismo hierro, la misma televisión que marcaban de superioridad a los países mecanizados. Se pasa a socializar y a universalizar el producto de la máquina. (Do Pau-Brasil 152)

\section{Obras citadas}

Andrade, Oswald de. Do Pau-Brasil á antropofagia e as utopias.

Río de Janeiro: Civilizaçao Brasileira, 1970.

- Ponta de lança. São Paulo: Globo, 1991.

Avellar, José Carlos. O cinema dilacerado. Río de Janeiro: Civilizaçao Brasileira, 1986.

Callado, Antonio. Quarup. Río de Janeiro: Civilizaçao Brasileira , 1971.

Favaretto, Celso. Tropicália: alegoria, alegria. São Paulo: Kairós, 1979.

Gerber, Raquel, René Gardies, René, eds. Glauber Rocha.

Río de Janeiro: Paz e Terra, 1977.

Hirszman, Leon. É bom falar. Montagen de entrevistas de Arnaldo Lorençato e

Carlos Augusto Calil. Río de Janeiro: Centro Cultural Banco do Brasil, 1995.

Buarque de Hollanda, Heloísa. Impressões de viagem: CPC, vanguarda e desbunde: 1960/70. São Paulo: Brasiliense, 1981.

Ortiz, Renato. A moderna tradição brasileira. Cultura brasileira

e indústria cultural. São Paulo: Brasiliense, 1988. 
Ramos, Alcides F. Canibalismo dos fracos. Bauru: Edusc, 2002.

Ridenti, Marcelo. Em busca do povo brasileiro: artistas da revolução, do CPC à era da TV. Río de Janeiro: Record, 2000.

Rocha, Glauber. Revolução do cinema novo. São Paulo: Cosac Naify, 2004.

Santiago, Silviano. O cosmopolitismo do pobre. Belo Horizonte: UFMG, 2004.

Santos, Milton. A natureza do espaço. Técnica e tempo. Razão e emoção. São Paulo: Hucitec, 1996. 